\title{
Formulating Policy Responses to Global Warming in the Face of Uncertainty ${ }^{1}$
}

\author{
HARRY CLARKE ${ }^{2}$
}

\section{Abstract}

The effects of risk and uncertainty on climate-change policy design are analysed. It is argued that while the science of climate change involves a consensus that anthropogenic greenhouse-gas emissions are driving higher temperatures and a changed global climate, there remains uncertainty about the extent of such changes and the risk of catastrophically large temperature increases in the absence of emission mitigation. The possible cost consequences of not addressing climate change are much greater than the costs of addressing it so that, from a range of perspectives, activist mitigation policies make sense. A critical assessment of Australian climatechange policy is provided, emphasising the key specific uncertainties that impact on policy design.

\section{Introduction}

The paper is concerned to discuss three aspects of climate-change policy. The paper begins with the role of uncertainty in the background science. A distinction is raised between the role of the explicit scientific uncertainty that forms such an important part of the work of the Intergovernmental Panel on Climate Change (IPCC), and the contrived uncertainty promoted by those that will be referred to here as 'climate-change delusionists'. The paper then turns to the broad economics of climate change, with a focus on the impact of risk and

\footnotetext{
1 This paper is based on a presentation to a meeting of the Economic Society of Australia, Victorian Branch. I thank Des Moore and those who attended for the ensuing enjoyable, vigorous debate. Without implication, I also thank Editor William Coleman, John Quiggin and two anonymous referees for their comments.

2 La Trobe University, H.Clarke@latrobe.edu.au.
} 
uncertainty on our understanding of climate-change economics. There follows a critical appraisal of Australian climate-change policy, emphasising the role of uncertainty.

\section{Climate science, climate uncertainty and climate delusionism}

\section{Scientific consensus}

Modern climate science developed in the early nineteenth century from observations in the 1760s by Horace Saussure about how actual greenhouses trap the sun's heat. In the early nineteenth century it was suggested that components of the atmosphere trapped heat energy analogously to the way a greenhouse did so. These ideas were developed by famous scientists and mathematicians of the day including Joseph Fourier, John Tyndall and others. In important work around 1895, Svante Arrhenius linked the heating effect of the atmosphere to the logarithm of its $\mathrm{CO}_{2}$ concentration. Subsequent work identified other socalled greenhouse gases, while atmospheric physics provided a theoretical basis for understanding the global-warming issue in terms of the vibration rates of certain gas molecules in the atmosphere (IPPC 2007: 103-6).

The predictions of this theoretical work are supported by the evidence. It is now certain that warming is occurring - this is a matter of fact — and, with high probability, that the warming that has occurred since pre-industrial times is due to the accumulation in the atmosphere of anthropogenic 'greenhouse gas emissions' (GGEs). These emissions are linked to the burning of carbonbased fossil fuels, such as coal and oil, and also to modern agriculture and landclearing activities.

The consensus of scientific opinion suggests that, ignoring slower feedbacks, the doubling of $\mathrm{CO}_{2}$ concentrations in the earth's atmosphere over pre-industrial concentrations will bring about an approximate expected mean global surface temperature increase of about $3^{\circ} \mathrm{C}$ - the Charney sensitivity. ${ }^{3}$ This increase will be more intense in the earth's Polar Regions and there will be substantial regional variations.

$\mathrm{CO}_{2}$ concentrations have grown from 280 parts per million ( $\mathrm{ppm}$ ) in pre-industrial times to 379 ppm in 2005 (IPPC 2007: 2). Growth rates in global emissions over

3 The Charney sensitivity is defined as the global mean surface temperature anomaly response to a doubling of $\mathrm{CO}_{2}$, assuming that surface, ice sheets and atmospheric composition (chemistry and aerosols) stay the same (National Academy of Sciences 1979). 
the last two years have been distorted, in a temporary and inessential way, by the effects of the global financial crisis on demands for carbon-based fuels. However, projecting smoothed emission-growth trends, and ignoring the impact of an active global mitigation program, a doubling of $\mathrm{CO}_{2}$ concentrations over 2005 levels should occur in about 40 years.

\section{Science and uncertainty}

Much information has been accumulated about the process by which climate change is occurring. The degree of certainty regarding the anthropogenicwarming hypothesis has strengthened, although (paradoxically) the range of temperature forecasts from climate science remains substantial. The range of forecasts in the third and fourth IPCC Assessment reports has not narrowed. Increased knowledge has heightened awareness of uncertainties as much as certainties.

For example, the Charney temperature sensitivity reflects only a narrow range of short-run simple climatic drivers. This sensitivity assumes that land surface, ice sheet and atmospheric/aerosol ${ }^{4}$ compositions do not change in character or chemistry as climate change occurs, thereby providing positive feedback loops that further increase temperatures. Longer-run sensitivity measures such as Hansen's long-term sensitivity (the 'Earth System sensitivity' or 'ESS') allow these factors to vary and hence for the feedbacks to help determine climate (Hansen et al. 2008). The ESS suggests that global mean surface temperatures will rise $6^{\circ} \mathrm{C}$ with a doubled $\mathrm{CO}_{2}$ concentration but over a period of hundreds of years rather than a few decades. Decisions to include specific feedback effects in a sensitivity measure are based on the timescale and complexity of feedback processes. Until recently, slow feedbacks have been excluded, as have complex feedbacks due, for example, to changed ozone/aerosol concentrations. In principle, the ESS could be estimated from paleoclimatic records but this requires good data on global temperatures as well as on the various climate forcings that operated over extended periods. This data is difficult to obtain.

Science does not have perfect information about how climate sensitivities vary with time horizon and with the various forcings. For example, some feedbacks drive higher sensitivities and aerosol clean-up may 'unmask' greater heating. For example, ice-sheet melting, as a consequence of warming, creates stronger long-run heating responses through reduced albedo (heat reflection) effects.

4 Aerosols comprise the suspended fine solid particles or liquid droplets in a gas. Examples are smoke, oceanic haze, air pollution and smog. Industrial aerosols absorb and scatter solar radiation and can have heating as well as cooling effects on the atmosphere. 
A fear held by many is that the current climatic situation is deteriorating. That 11 of the 12 years over the interval 1995-2006 were among the 12 warmest since 1850 highlights concerns about sensitivity assessment (IPCC 2007: 5). Moreover, the growth in temperatures has continued beyond 2006. BOM data indicate that Australia's annual mean temperature for 2009 was $0.9^{\circ} \mathrm{C}$ above the $1961-90$ average, making it the nation's second-warmest year since high-quality records began in 1910 (BOM 2010).

It is worth emphasising that modern climate science makes no attempt to conceal uncertainties in knowledge. The IPCC Assessment reports focus on uncertainty with, for example, extensive discussion of the problematic role of clouds, aerosols, Antarctic sea ice and so on as climate drivers. Indeed, in The Physical Science Basis Report (IPCC 2007: 81-91) there are 43 key uncertainties listed in relation to natural/human climate drivers, six on global projections, two on sea-level changes and three on regional forecasts. ${ }^{5}$ None of these issues are minutiae. It is therefore wrong to portray institutions such as the IPCC as comprising propagandist 'greenies'.

\section{Delusionism}

The key doubt some sections of the media and certain interest groups seek to promulgate is whether the entire science of climate change is wrong. The science would be wrong if it were not the case that human beings are significantly altering the world's climate - if the anthropogenic global-warming hypothesis $(\mathrm{AGWH})$ was false because the warming that has been observed is natural.

This question of the believability of the science was examined in the Garnaut Review (2008). In a recent speech Garnaut (2009) commented:

The Review accepted the views of mainstream science 'on a balance of probabilities'. There is a chance that it is wrong. But it is just a chance. To heed instead the views of the small minority of genuine sceptics in the relevant scientific communities would be to hide from reality. It would be imprudent beyond the normal limits of human irrationality.

This seems indisputable. It seems sensible to act on the presumption that the mainstream science is correct and imprudent to suppose otherwise.

Oreskes (2009) confirms Garnaut's presumption that almost all climate scientists support the AGWH. In a bibliographic survey, she found no explicit rejections of the hypothesis in the published scientific literature. Specifically, of 928

5 Key uncertainties include the radiative effects of aerosols, reasons for recent changes in $\mathrm{CH} 3$ concentrations, land-atmosphere interactions that lead to radiative forcing, disagreements on the role of cloud cover and in situ ice cover and trends in glacier ice loss. 
abstracts containing the keywords 'global climate change' in the database of the Institute for Scientific Information (ISI) from 1993-2003 not a single paper provided scientific data to refute the consensus scientific position on climate change.

There is a group of contrarians but they are not now doing scientific research on this topic. In a further recent study, Doran and Zimmerman (2009) found overwhelming support for the AGWH, with 75 out of 79 self-described 'climatologists' — out of 10,257 geoscientists in US federal research facilities affirming belief in AGWH. Quoting Doran and Zimmerman (2009):

It seems that the debate on the authenticity of global warming and the role played by human activity is largely nonexistent among those who understand the nuances and scientific basis of long-term climate processes. The challenge, rather, appears to be how to effectively communicate this fact to policymakers and to a public that continues to mistakenly perceive debate among scientists.

The consensus view in science may be incorrect, as it was historically with respect to Alfred Wegener's theory of continental drift. But such historical examples only reinforce the need for humility - the scientific consensus may be wrong ${ }^{6}$ and there may be a need to revise views as knowledge advances but, as yet, no new knowledge has arisen seriously questioning AGWH.

As noted, doubts about AGWH do not reflect the state of science. There is, however, a mistaken public perception that there is a substantial scientific debate. It is worthwhile trying to understand how this false perception has developed.

The politics of climate change was decisively driven by Revelle and Suess (1957), which identified global heating caused by anthropogenic $\mathrm{CO}_{2}$ emissions as a significant policy concern. In the words of these authors, human use of fossil fuels amounted to a 'large scale geophysical experiment'. Through to the early 1990s there was a consensus of international political opinion supporting AGWH that led to the 1992 Climate Convention and to an ongoing role for the IPCC.

From the late 1980s, however, organised groups emerged who denied AGWH and who sought to force a public debate on whether AGWH was believable. These comprise a tiny group of respectable sceptical scientists, such as the atmospheric

6 It is sometimes argued that a consensus has low informational value if individual scientists irrationally 'borrow' each other's views. For this to have force it must be shown that such irrational borrowing occurs. The evidence suggests independence of view, both on the basis of the range of independent institutions holding the same consensus attitudes and the bibliographic studies cited which reject the major competing alternative hypothesis - that the warming which is occurring is 'natural'. 
physicist Richard Lindzen; a larger group who, for a living, manufacture delusions on many topics; and a much larger group of conservatives who accept ideologically convenient delusions. These groups interact to a considerable extent. I label them as 'delusionists'. These well-funded groups have worked to create and disseminate uncertainty, ignorance and confusion on climate-change issues. They have been extraordinarily successful, with much of the political right in Australia and almost all in the US being deluded into thinking the climate-change problem is illusory. In Australia, most National Party MPs, many in the Liberal Party, a few in the Labor Party and some academics in universities endorse delusionism.

The delusionist groups are an influential political movement which promotes the rejection of mainstream science. In the US, these groups centre on the George C. Marshall Institute and the Heartland Institute. In the past, these groups have suggested that passive smoking may not cause health damage, that CFCs in the atmosphere did not cause the hole in the ozone layer, and that SO2 did not cause acid rain. None of these claims stand up to scrutiny. Furthermore, it is a matter of public record that these groups have in the past received funding from Exxon-Mobil, and their officials (Fred Singer and Frederick Seitz, for example) have worked as consultants for the tobacco companies and written reports suggesting that secondary tobacco smoke might not be harmful to health.

Australian delusionism draws heavily on British and American delusionism. An important local offshoot is the Lavoisier Group, ${ }^{7}$ which has enjoyed success in influencing public opinion beyond its due.

A major activity of delusionist groups is to create the false impression of a substantive debate in climate science. As Oreskes (2007) and Doran and Zimmerman (2009) show, there is none. The false implication that there is a substantive debate is further twisted to suggest that the case for activist climate policies is somehow weakened by the existence of such a debate. The implication that the false doubt undermines the case for activist policy is an invalid conclusion in several senses. Most importantly, with correctly specified uncertainty, things might indeed be 'worse' — not 'better' — than expected as is discussed below, thereby intensifying the case for activist climate-change policy.

A disturbing feature of delusionist activity is the repetition of discredited or heavily criticised viewpoints. An example is the repeated reputed claim that global warming stopped during the 10 years after 1998. This was rejected using evidence collated during the preparation of the Garnaut Review and by statisticians and climate scientists on numerous occasions since then. The

7 For discussion of Lavoisier's origins, see http://www.lavoisier.com.au/lavoisier-about.php. 
claim is still repeated mostly without any reference to the contrary claims by eminently qualified statisticians and climatologists (Breusch and Vahid 2008; Fawcett and Jones 2008) who show that the claim is unsupported by evidence.

Delusionism is fostered in Australia by spurious notions of 'press balance', according to which any view, no matter how far-fetched, has a right to equal treatment in the public domain. Academics, such as the geologist Professor Ian Plimer, promote delusionism in Australia through books such as Heaven and Earth (2009), which deny AGWH. According to his academic website, Professor Plimer has never published a refereed scientific paper in the field of climate science. ${ }^{8}$ Indeed, the analysis of Plimer's book is inconsistent with science.

As an economist, it is not my right or role to question the veracity of mainstream science. Indeed, I generally refuse to debate the mainstream science of climate, and believe that economists whose policy preferences are secured by rejecting science have lost their bearings. I do, however, read the science, and am familiar with the arguments advanced by delusionists. Rebuttals to their arguments are simple to find in the scientific literature (for example, IPCC 2007). There is no more reason to question the validity of science than to take seriously the crank monetary theories sometimes pushed by physicists. ${ }^{9}$

\section{Climate-change economics}

Climate-change economics seeks to determine the economic impacts of unmitigated climate change and the costs of mitigating and/or adapting to it, either at the global level or at the level of an individual project such as, for example, a forest planting. Given these estimates, the case for policy reverts to a cost-benefit analysis based on opportunity costs. What are the costs of pursuing active climate policy compared to the costs of not doing so?

Inputs into this endeavour include information from science-based models that link the emission of greenhouse gases to climate changes and to the damage functions that suggest the costs that will be inflicted by such temperature changes. There is also a need to forecast the human responses, such as climatic adaptations and the induced innovations that will be associated with climatic changes. This is an ambitious task.

8 See http://www.ecms.adelaide.edu.au/civeng/staff/iplimer01.html\#research.

9 This line of argument was suggested to me by John Quiggin. An example of a crank-physicist economic theory is Frederick Soddy's critique of fractional reserve banking (Zency 2009). 


\section{Cost benefit analysis}

There are problems of valuing the damages climate change will inflict on societies and, with demand and technology uncertainties, the costs of policies designed to offset such damages. But even ignoring such valuation issues, the complexity of climate-policy analysis is driven by its formal character as a particular instance of cost-benefit analysis (CBA). The ingredients of this CBA involve several types of irreversibility coupled with learning processes, nonlinear responses and threshold effects, all thrown together in an intrinsically dynamic setting where uncertainty is an intrinsic ingredient. Such CBA tasks can be analysed in a distinctive 'real options' setting (see Pindyck 2006; Dobes 2008).

Analysts are highly uncertain about the extent of likely climate change, of associated costs and hence of the viability of various technological fixes such as carbon-capture and storage (CCS) technology. They have information about these issues but can expect to learn more as the future unfolds. Thus, information about climate evolution and valuations are stochastic processes. These learning dynamics supplement the uncertain intrinsic dynamics associated with the accumulation of the stock GGE pollutants in the atmosphere.

There are also potential sun-cost irreversibilities and non-linearities associated with threshold effects. First, sunk costs associated with investment designed to address climate-change effects will involve irretrievable waste should business-as-usual climate-change costs prove less costly than forecast. These irreversibilities motivate policymakers to delay and de-intensify policy responses until better information becomes available. They are partially offset by the increasing costs of abatement that can arise with delays in responding. For example, incurring the incremental costs of expanding electricity supplies using new carbon-friendly technologies (solar, nuclear) are lower than replacing pre-existing carbon-intensive technologies with those that are carbon-friendly. Delay therefore locks in emissions-intensive infrastructure which constrains future abilities to mitigate. This is especially true for developing countries where incremental costs of energy capacity are much lower than replacement costs (Office of Tony Blair 2009).

There are also irreversibilities associated with potential threshold effects that give rise to catastrophic outcomes. With respect to biodiversity conservation, species extinctions induced by climate change are irreversible costs, while steadily worsening climate change generally might induce non-linear cost responses if ice sheets or the Arctic permafrost melts. Provided that policy actions can address these concerns, the prospect of such phenomena motivates policymakers to seek prompt and intense responses. 
The differing sunk-cost and environmental irreversibilities tug policy analysis in opposite directions. The sunk-cost irreversibilities encourage delay in order to learn, while the prospects of catastrophic irreversibilities motivate decisive action now. Pindyck (2006) has sought via numerical simulations to find out which effects dominate - his emphasis is on sunk-cost effects — but, as he has no actual data, his arguments are unpersuasive. Similar comments apply to work by Kolstad (1994 and 1997) emphasising the role of sunk costs.

Some policy insights can be formulated on the relative effect of the two irreversibilities. A policy measure which reduces sunk costs increases the case for immediate, decisive action. For example, sunk-cost irreversibilities are lower if investments provide benefits, even if climate change should prove to be less damaging than expected - this is equivalent to Kolstad's (1994 and 1997) case for using reversible policy tools as a 'no regrets' option. ${ }^{10}$ Clean-power technologies provide useful local environmental benefits in terms of reduced air pollution, while enhanced biodiversity-conservation programmes provide valuable spill-over benefits in promoting agricultural sustainability even should they prove to be based on overly pessimistic climate assumptions. Less of the costs in these situations are now sunk.

Reducing the prospects of catastrophic damages on the other hand delivers increased flexibility for policymakers by putting less weight on feared outcomes. Geo-engineering carbon clean-up options even at high cost, or costly captivebreeding programmes of endangered biodiversity to limit species extinctions, provide a backstop technology that gives policymakers extra time to learn about prospects and implications of severe climate change.

As a general theoretical paradigm, policymakers should think of climatechange issues using this 'real options' perspective that accounts for risk and these irreversibilities. This amounts to using CBA under conditions of risk where irreversibility interacts with structural and learning dynamics. It is inappropriate to account for uncertainty by replacing random variables by their expected values since the effects of waiting to learn and of delay must be accounted for.

\section{Discounting}

What weight should be placed on the welfare of people today relative to that of their children and of future generations? Should market or intergenerational equity-based discount rates be used in valuing future costs and benefits? This

10 It is difficult, however, to agree with Kolstad's arguments for temporary rather than permanent taxincrease measures since these will not lead to the types of long-lived investment decisions one would hope energy-supply agencies would make. 
is a matter of practical importance. Stern (2007) uses a discount rate of 1.4 per cent which values a dollar to be received in 32 years at $\$(1.014)^{-32}=73$ cents. Nordhaus (2008) prefers 3 per cent, putting a current valuation on a dollar of $(1.03)^{-32}=38$ cents.

It is important to understand that a 3 per cent choice has major intra-generational implications. Such a choice puts a weight of only 0.38 on my 11 -year-old son's welfare in 32 years, and that is subjectively less than I think is appropriate. Hence, a 3 per cent discount rate is too high for me and my intra-generational objectives. I am more comfortable with low Stern-type discount rates because I wish to provide a sound environmental future for my children.

The choice of discount rate is an uncertain issue but the convexity of the discount factor in the discount rate means that, if an expected rate is to be used, it should be 'small' (Pindyck 2007). Thus, suppose the expected present value of a $\$ 100$ benefit to be received 100 years from now is to be determined but that the discount rate is either 0 or 10 per cent each with probability $1 / 2$. At the expected discount rate, 5 per cent, $\$ 100$ has a present value less than $\$ 1$. But the expected present value is $1 / 2(\$ 100)+1 / 2(\$ 0)=\$ 50$ and the discount rate applied to a $\$ 100$ benefit to be received in 100 years that yields a present value of $\$ 50$ is 0.7 per cent. Thus even though the expected value of the discount rate is 5 per cent, uncertainty over its value implies an effective discount rate of less than 1 per cent.

\section{Risky damages}

Furthermore, environmental damages themselves are certainly convex in future temperatures - they increase with higher temperatures at an increasing rate. Therefore suppose the IPCC forecast of a $3^{\circ} \mathrm{C}$ increase in global mean surface temperature is associated with moderate economic damage equivalent, for example, to 5-10 per cent of GDP depending on how environmental damages are assessed. If the IPCC forecast is a mean forecast it can be interpreted as a forecast of $2^{\circ} \mathrm{C}$ with 50 per cent probability and $4^{\circ} \mathrm{C}$ with 50 per cent probability, or if there is greater uncertainty, as a forecast of $0^{\circ} \mathrm{C}$ with 50 per cent probability and $6^{\circ} \mathrm{C}$ with 50 per cent probability. Without warming there are no damages but with an equal probability of warming of $6^{\circ} \mathrm{C}$ there would be catastrophic costs that should be avoided. More risk - in the sense of a mean-preserving increased variance in forecast temperature changes - implies a stronger case for effective climate-change policy action whenever catastrophically large costs are associated with high temperature increases.

This issue can be looked at in a different way. Suppose there are various possible future climate states contingent on current climate policies but one state where catastrophic costs (for example, melting of the Greenland ice sheet and hence 
drastic sea-level rises) occur with non-negligible probability. Then, rational policymakers who can have any significant impact on global outcomes should act to avoid that state irrespective of discount rates or even strategic concerns in relation to the policies of other countries. The prospect of preventable catastrophes at non-negligible probabilities favour unilateralism and prompt policy action in relation to climate change (Clarke 2010; and Clarke and Reed 2006).

\section{Knightian uncertainty}

These probabilistic insights depend on the assumption that information about probabilities can be provided by climate science or that at least subjective probabilities can be assigned. Insights can, however, be sought in settings with pure Knightian uncertainty without probability information.

Clarke (2008) suggests use of classical decision rules not involving use of even subjective probability information. Thus the Precautionary Principle (PP) can be understood as an attempt to avoid severe costs by introducing policy to avoid the worst possible outcomes. This is a version of the classical Minimax Principle which seeks to select the least bad possible outcome. This plausiblesounding heuristic is, however, unhelpful unless the policymaker can be certain that costly policy, once it needs to be undertaken, will not fail. This assurance is difficult to provide. Unless a policy is known with complete certainty to be effective, the most costly contingency is undertaking a costly policy which fails, in the event, to deal with climate change. Thus, from this perspective, PP would provide the counterintuitive direction to remain policy-inactive, irrespective of the policy problem or the available policy instruments.

An alternative heuristic that underlies much modern policy thinking and which lends conditional support for policy activism is Minimax Regret. Here, policy interventions are undertaken if unmitigated climate change occurs, involving substantial costs which could have been avoided at much lower cost, thus potentially creating regret. This heuristic provides a probabilityfree insurance heuristic that many of us doubtless use in everyday life - we insure our homes against fire damage not by using subjective probabilities and cost data but because we see that the costs of a fire will be vast compared to the insurance cost. Inexpensive policy will now be undertaken if it addresses concerns that might have vast cost if left unaddressed; and if climate change proves not to be as serious as thought, the opportunity losses are low. This case for policy disappears if policy costs are only 'somewhat' less than the costs avoided without policy but, as is argued below, empirical evidence from various perspectives confirms that in a climate-change setting policy costs are much lower than possible costs of not taking action. 
Earlier work along these lines by Arrow and Hurwicz (1972) showed that, under ignorance, choices based on extreme outcomes satisfy plausible rationality criteria. This work was implemented in a climate-change policy-decision context by Woodford and Bishop (1997). Here a 'panel of experts' was portrayed as offering divergent opinions and a policymaker had to choose between them without being able to assess which was more likely to be correct. Without allowing for the possibility of policy failure, the work suggested a case for strong immediate control action to address catastrophes followed by a switch to less-intensive policies if evidence eventually suggested small damages. This is broadly consistent with the arguments made above, although inconsistent with those of Kolstad (1994 and1996).

Finally, there are heuristic reasons for responding to policy uncertainty by both diversifying choice of policy options and by retaining, as an option, the facility to introduce, perhaps expensive, backup policies if all else fails. In climate-policy settings, various policy approaches should be employed without a telescopic committed focus to a particular approach. Where possible a portfolio of policies should be explored and policy choice should be adaptive and sensitive to the unexpected. Backstop insurance options should be researched, and retained as longer-term options, should current policy fail. For example, if mitigation options fail to be effective, geo-engineering approaches involving, for example, direct removal of $\mathrm{CO}_{2}$ from the atmosphere can provide a backstop technology as insurance against disaster. Hansen et al. (2008) conjecture that, at \$200/tC, $\mathrm{CO}_{2}$ can be directly removed from the atmosphere. The cost of a once-and-forall removal of $50 \mathrm{ppm}$ of $\mathrm{CO}_{2}$ globally would be $\sim \$ 20$ trillion, which is of the order of 150 per cent of US GDP in 2009. Such policies can be unilateral and implemented by a wealthy superpower without the 'free-rider' issues that thwart more-conventional mitigation strategies that rely on international cooperation.

With respect to biodiversity conservation, proposals to strengthen existing reserves by expanding their size in isolation might be pursued to minimise the risks arising from unsought species migrations. Other strategies that should also be independently considered involve almost the opposite strategy of linking up existing reserves to facilitate sought migrations (see Dunlop and Brown 2008). If these strategies jointly appear likely to fail, an expensive backstop is a captivebreeding programme.

On secondary energy technologies there are substantial uncertainties on the commercial potential of low- $\mathrm{CO}_{2}$ technology options and fourth-generation nuclear power. There are, for example, specific issues of the economic viability of CCS which would not seem to be economic at carbon prices much less than US $\$ 60 /$ ton. At this stage, a portfolio of technologies (renewable, nuclear) should be researched, with a focus on CCS. 
Focusing on CCS alone and on renewable technologies such as solar and wind is imprudent given the imperatives Australia will face to cut its GGEs dramatically by 2050. The possibility of a major shift toward nuclear fuels should be entertained. Nuclear fuels have potential economic advantages over coal, gas and wind technologies once environmental costs are accounted for, and nuclear power involves negligible $\mathrm{CO}_{2}$ emissions. In 2004 France generated slightly less than 80 per cent of its electricity using nuclear power and emitted about 9.3 tonnes of $\mathrm{CO}_{2}$ per head in 2003. Australia that year emitted 26.1 tonnes of $\mathrm{CO}_{2}$ per capita (figures from the UN's Globalis websites). Suppose, then, that the world agrees to reduce its aggregate carbon emissions from 50 mega-tonnes now to less than 20 mega-tonnes by 2050 to avoid more than $2^{\circ} \mathrm{C}$ of warming. This amounts to 2.2 tonnes per person in 2050 with an estimated world population of 9.1 billion assuming equal per-capita entitlements. To achieve this, France would need to cut its GGE emissions to less than 23.9 per cent of current levels. Australia, however, would need to cut its emissions by about 71 per cent of current levels!

Despite the uncertainties concerning various particular aspects of climatechange economics, there is an economic consensus on these issues that parallels the consensus in climate science. Most economists agree, for example, that while some countries benefit most lose with limited climate change. All lose with substantial change because positive effects on agriculture then disappear (Stern 2006: 62).

In addition, even with substantial uncertainties there is a presumption that the cost of active policy is low relative to the cost of doing nothing. As evidence, note that the Stern Review (2007) estimates the cost of stabilising at 500-550 ppm at approximately 1 per cent of world GDP, whereas the costs of not addressing climate change are 20 per cent of GDP. The IPPC (2007b) estimates the 2030 costs of stabilising at from 445-535 ppm at less than 3 per cent of GDP, with ongoing growth of GDP reduced by less than 0.12 per cent. Nordhaus (2008) targets lower levels of cutback than does Stern (and Nordhaus is very critical of Stern's pessimism) but nevertheless estimates optimal costs of abatement at only 0.1 per cent of discounted world income. Finally, Weitzman (2009) focuses on possible catastrophic costs of not abating. Gradually ramping up climate-change policies over the next 200 years creates significant global catastrophic risks and huge costs. There is a 5 per cent probability of a mean global surface temperature increase of greater than $10^{\circ} \mathrm{C}$ and a 1 per cent probability of an increase of greater than $20^{\circ} \mathrm{C}$.

These studies employ distinct modelling strategies, but a consensus is that mitigation costs are low relative to the costs of not addressing climate change. 
While this is a basis for optimism, GGEs have grown by 70 per cent from 19702004. Most growth has come from the global electricity sector (145 per cent) (IPCC 2007). Global energy intensities - energy consumption per unit output - have decreased but not by enough to avoid being influenced by the effects of income and population growth. GGE mitigation policies have not yet worked to stall emissions growth. Moreover, policies as they currently stand will fail. From 2000-2030, GGEs will grow strongly, with three-quarters coming from developing countries. There is no basis for complacency.

\section{Australian climate-change policy}

Australia will be impacted on heavily by unmitigated climate change because it is a 'fringe climate' society. Australia has high gross per-capita emissions but is a 'small' country in terms of aggregate GGE emissions. Globally, the US and China provide 50 per cent of total GGEs, another 15 countries provide a further 30 per cent and another 158 provide 20 per cent (Baumart 2005). Therefore, in aggregate, small countries such as Australia are important polluters. In addition, for a viable global climate-change response post-Kyoto, poor and developing countries must begin to mitigate emissions in the medium term. Australia should not provide negative moral suasion by refusing to accept its share of the international policy response (Clarke 2009).

Australia's policy position can be exposited in terms of its mitigation and adaptation policies as well as its attitude toward forthcoming international climate-change agreements.

\section{Mitigation}

Governments can employ various policy instruments to encourage GGE cuts. They can, for example, prescribe energy-consumption or energy-production targets. Economic instruments, which rely on price changes to induce changes in emission behaviour, have advantages over prescriptive targets. Pricing GGEs generates broad supply-and-demand responses to climate problems that reflect both energy prices and the costs of altering emission behaviour. Prescriptive target-setting is a more expensive policy because regulators cannot identify the costs different agents face in meeting these policies.

There is a debate about the case for using a GGE tax or a national emissiontrading scheme (ETS) based on targeted aggregate emissions. There are costs and benefits with each approach, although choosing either policy is a decisive advance over choosing neither. For the most part, choice between these policies is an issue of second-order importance. Setting carbon prices by imposing a 
tax means that the extent of mitigation will be uncertain, which is unattractive if a particular level of emission cuts is sought. Setting emission quotas using an ETS will leave carbon prices buffeted by market conditions, creating price uncertainty and futures markets in carbon quota sales. With an ETS, carbon prices will show significant month-to-month variations that make investment planning in firms more difficult, although longer-term carbon prices that fall during periods of recession and which increase during booms provide an automatic macroeconomic economic stabiliser. The claim that carbon taxes make it difficult for interest group bargaining to secure exemptions is unproven - it is as easy to argue for a tax break as a free emissions permit. If either tax revenues or revenues from auctioned quotas are used to cut other more distorting taxes then further double-dividend advantages may accrue.

An advantage of a global ETS is that improved opportunities to trade permits mean lower mitigation costs: costs are estimated to fall by 20 per cent with a global ETS, as opposed to a set of independent national schemes (Office of Tony Blair 2009).

The proposed Australian carbon-pollution reduction scheme (CPRS) is an ETS which will be phased in with unlimited permits at $\$ 10 / \mathrm{tCO}_{2}$ from $2011 / 12$, with full permit auctioning from $2012 / 13$ at what is expected to be around $\$ 29 / \mathrm{tCO}_{2}$. This will yield revenues of about $\$ 13 \mathrm{~b}$ in $2012 / 13$ which will be returned to households (\$5b), fuel-excise offsets (\$2.2b), trade-exposed firms (\$3.6b) and to electricity generators (\$0.8b) (DCL 2009). Caps will be pre-announced for the first few years but subsequent caps will depend on 2020 targets that will be determined once the rest of the world announces its cutbacks.

The structure of the CPRS is production-based, with some free quotas allocated to trade-exposed firms and generators of non-traded secondary energy and with income compensations for electricity consumers that make consumers respond only to the pure substitution effects of electricity price changes. Indeed electricity prices will rise about 25 per cent in 2012/13, with consumers being partly income-compensated for the higher prices.

There will be significant longer-term impacts of the CPRS on coal, which is both Australia's main source of electrical energy and its biggest export. There are strong effects on brown-coal generators, although 93 per cent of such capacity will be in place by 2020 (Garnaut 2007: 491). There is the potential for substitution by nuclear power and renewables although there is limited engineering capacity to introduce nuclear technology - there is no school of nuclear engineering at any Australian university. As noted earlier, given the cost uncertainties, a mix of alternative-energy sources ex ante makes sense given that the alternatives have cost advantage at differing carbon prices and interest rates. As Garnaut stresses, there are significant potential payoffs to developing 
'clean coal' (CCS) in cutting our own emissions and in securing valuable export markets. At present CCS is a technically feasible technology but its commercial potential remains unclear.

The CPRS is a useful start at providing a comprehensive demand-management policy, although it can be improved.

The scheme as it stands is production-based but its free quota distributions give it a partial consumption basis. A better scheme would begin with a CPRS based on consumption so that carbon-intensive exports were exempted from the need to comply with emissions quotas and with all carbon-intensive imports from countries which do not impose comparable carbon-emission controls on a production basis being subject to a border tax. Such BTAs are probably not inconsistent with the rules of the GATT (Tamiotti et al. 2009) since they operate essentially as a consumption tax. Such a scheme would resemble the longerterm ETS proposed in the US by the Waxman-Markey Bill. The consumption base provides incentives for other countries to tax their exports on a production basis and, in the longer-term, when enough do so, Australia too can switch to a production-based tax without either exemptions for exports or border taxes on imports.

Consistent with this position, there should be no free carbon permits to Australian electricity producers. Exporters which use electricity as an input would be eligible for rebates.

In addition, it has been pointed out that voluntary action to reduce GGE emissions will be ineffectual since the effect of such actions will be to reduce the carbon price. This can be most easily addressed by buying back 'saved' allowances, by reducing emission caps, or by more-elaborate schemes such as the CEEM's Additional Action Reserves (Betz 2009).

The policy of assigning firms free carbon quotas has the undesirable consequence that such quotas must be used to be effective. It would be better to make such quotas tradeable and to then use the revenues to fund energy-saving adjustments.

Finally, there is probably no need for explicit renewable targets - and inefficiencies might stem from setting such targets - if the 2020 carbon price is around $\$ 50 /$ tonne. Markets will then efficiently determine the viability of noncarbon-based energy technologies with such a carbon price.

If markets worked perfectly, then setting the correct carbon price would be all that is needed. However, market imperfections exist related to the supply of information to reduce uncertainties for consumers and producers and 
for developing and transferring new energy-saving and carbon-friendly technologies. These create a case for public support by providing information and through explicit subsidies. Such support will make the CPRS more effective.

A practical difficulty with the CPRS is that it has twice been rejected by the Australian Senate so that, as it stands, it cannot be introduced. Opposition to the CPRS has been led by the Federal Coalition parties who have denounced the CPRS as 'a big tax'. Paradoxically for a conservative political party, the Coalition has proposed, instead, a 'Direct Action Plan' of funding directly selected $\mathrm{CO}_{2}$ reductions by subsidising the provision of solar panels in homes, schools and communities, by establishing geothermal and tidal-power projects, by planting 20 million trees, and so on (Abbott 2010). The main disadvantage of this nonmarket-based scheme is that it will cost more than a CPRS tailored to meet similar reductions targets unless its designers have better information than do firms and households operating in energy markets.

\section{Adaptation}

Australia can pursue a timely, successful agreement to replace the Kyoto Protocol but would be foolish to assume that such an agreement will be either prompt or entirely successful. Plausibly, the world can expect $1.8-2^{\circ} \mathrm{C}$ warming over pre-industrial temperatures from existing GGE concentrations, so there is a case for policies which seek an adaptation to climate change in agriculture, industry, urban settlements and in the conservation of Australia's biodiversity resources.

Adaptation investments are not subject to the 'public goods' market-failure issues associated with mitigating climate change although, if mitigation is undersupplied globally, private incentives to adapt to many aspects of climate change are enhanced on the basis of private self-interest. Conversely, incentives to mitigate are reduced when active adaptation policies are in place but, if adaptation policies alone are pursued globally, nations are engaged in a race toward collective disaster.

With respect to adaptation, there is therefore greater potential to rely on marketdriven responses and on policy responses which seek to encourage marketdriven responses. In agriculture, for example, it has been widely observed that farmers are skilful at adapting to climate uncertainties. Indeed, their livelihood often depends on the capacity to make such adaptations. Provided that climate change is not proceeding too quickly, that prices for current outputs are not deteriorating too rapidly, and that they can revise their production plans quickly enough, farmers can make market-based adaptations that will come close to optimising their welfare. The only role for public policy is to provide climate information and to expand the range of technological options farmers have as they experience climate change (Clarke 2009). Public-good market failures mean 
that these informational investments to reduce uncertainty, as well as $R \& D$, need to be a focus. Of course, policies which reduce the need to adapt - such as 'exceptional circumstances' drought relief - need to be either redesigned, or as the Productivity Commission (2009) has suggested, abolished.

Urban-sector adaptations involve planning water and wastewater infrastructure expansions, and transport network designs need to be configured so climate change is either factored into the expansion decision or options are left to expand eventual capacity at low cost, again to deal with hot states of the world. There is also a role for public planning with respect to concerns regarding disaster preparedness.

Many other issues can also be market-driven, again on the basis of campaigns to increase private-sector awareness of the implications of climate change. Choices such as roof colour, the use of insulation and location of housing in relation to threats posed by changes in sea level are decisions best kept private on the basis of, perhaps, publicly boosted information about climate-change consequences and such things as opportunities for improved energy efficiencies.

Adaptation policies cannot always be primarily private. There are no markets for the supply of biodiversity in Australia, so market-based solutions will not work here. There is a need to manage the national reserve system while promoting conservation and corridors on private land (Clarke 2007). With respect to enhanced conservational investments there are significant 'no regrets' benefits, even if climate change proves less extensive than expected.

\section{Policies helping the global response}

Australia ratified the Kyoto Protocol on the 3 December 2007. This sent a good 'moral suasion' message about Australia's climate-change policy intentions even if it had limited immediate effect and even though the force of the Protocol will expire in 2012. In 2012 a new co-operative international agreement needs to be signed, and the Australian Government pledged a series of unconditional and conditional GGE reductions at the initial meeting, in Copenhagen in November 2009, to determine such an agreement.

The Australian Government was committed to match a comprehensive agreement in Copenhagen. If there was no agreement in Copenhagen, then Australia would offer an unconditional 5 per cent cut over 2000 GGE levels by 2020. If other countries target a 510-540 ppm GGE target by 2050, then Australia offers a conditional 15 per cent cut over 2000 levels by 2020. Finally, if other countries agree to target a $450 \mathrm{ppm}$ agreement then Australia would offer a conditional 25 per cent cut over 2000 levels by 2020, with up to 5 per cent by deforestation credits. 
The mix of conditional and unconditional targets is a reasonable approach to addressing uncertainties in the climate-change policies of other countries, even though the Green movement in Australia argued that still more ambitious targets of $330 \mathrm{ppm}$ or lower should have been pursued. This is not sensible if targeting such low GGE levels limits the potential for achieving any collective agreement at all. It seems more sensible to target emission cuts that are plausibly achievable now and to seek tighter cuts in the future.

To enhance the prospect of gaining cooperation from developing countries, Australia should agree to a common emissions entitlement per person by 2050 , as suggested in the Garnaut Review.

\section{Conclusion}

Economists should base their policy views on the mainstream science of climate change. This science makes explicit a range of significant uncertainties and involves, primarily, belief in the view that human beings are having a significant impact on the global climate. To avoid taking policy action on the basis of the implausible views of a handful of practising scientists who do not endorse this primary view would be folly.

The core economics of climate-change policy amount to comparing the opportunity costs of taking policy actions with the costs of not taking action. This is an ambitious field because there are significant issues of uncertainty, the setting is intrinsically dynamic and there are important non-linearities and irreversibilities. Conceptually, the way to proceed is to use cost-benefit analysis, which correctly accounts for uncertainty when there are significant irreversibilities.

Australian policy has made a credible start to initiating climate-change adaptations and mitigations locally and has a reasonable stance toward international negotiations. Ultimately, Australia needs a more comprehensive and integrated energy-use plan that will provide a closed-loop approach to commercialising non-carbon-polluting secondary-energy technologies. As the Garnaut Review makes clear, Australia gains enormously with CCS technology development and transfer, so this is a sound R\&D focus. Another sensible focus is agriculture, which is a significant contributor to GGE emissions but also promises carbon-sequestration synergies by means of sustainable agriculture.

Over the coming decades, Australia and other countries need to think about pursuing stricter GGE targets with the eventual aim of restoring pre-industrial GGE levels. This will eliminate longer-term impacts of GGE emissions on climate. 


\section{References}

Abbott, T. 2010, The Coalition's Direct Action Plan - Policy. Available at: http:// www.tonyabbott.com.au/Pages/Article.aspx?ID $=3932$.

Arrow, K. J. and Hurwicz, L. 1971, 'An Optimality Criterion for Decision-Making Under Ignorance', in Carter C. and Ford J. (eds), Uncertainty and Expectations in Economics: Essays in Honour of G. L. S. Shackle, Basil Blackwell, Oxford.

Australian Government Bureau of Meteorology 2009, Annual Australian Climate Statement. Available at: http://www.bom.gov.au/announcements/media_ releases/climate/change/20100105.shtml.

Baumert, K. A., Herzog, T. and Pershing, J. 2005, Navigating the Numbers: Greenhouse Gas Data and International Climate Policy, World Resources Institute.

Breusch T. and Vahid, F. 2008, 'Global Temperature Trends', College of Business and Economics, Working Paper No. 495, Australian National University, April.

Betz, R. 2009, 'The Concept of the Additional Action Reserve', Centre for Energy and Environmental Markets, University of New South Wales, Sydney, June. Available at: http://www.ceem.unsw.edu.au/content/userDocs/ AdditionalActionReserve.pdf.

Clarke, H. and Reed, W. 2006, 'Consumption/Pollution Tradeoffs in an Environment Vulnerable to Pollution-Related Catastrophic Collapse', in Hoel, M. (ed.) 2006, Recent Developments in Environmental Economics, Critical Writings in Economics, Elgar Reference: 497-516.

Clarke, H. 2007, 'Conserving Biodiversity in the Face of Climate Change', Agenda $14,157-70$.

Clarke, H. 2008, 'Classical Decision Rules and the Economics of Climate Change', Australian Journal of Agricultural and Resource Economics 52: 487-504.

Clarke, H. 2009, 'Carbon Leakages, Free Riders and International Climate Change Agreements', mimeographed, September.

Clarke, H. 2010, 'Strategic Issues in Global Climate Change Policy', Australian Journal of Agricultural and Resource Economics 54(2): 165-84.

Department of Climate Change 2009, Revised Fiscal Impact of the Carbon Pollution Reduction Scheme (CPRS), Fact Sheet, Department of Climate Change, Canberra, May. 
Dobes, L. 2008, 'Getting Real About Adapting to Climate Change: Using "Real Options" to Address the Uncertainties', Agenda 15(3) 55-72.

Doran, P. and Zimmerman, M. 2009, 'Examining the Scientific Consensus on Climate Change', Eos 20, January 2009.

Dunlop, M. and Brown, P. 2008, 'Implications of climate change for Australia's National Reserve System: A Preliminary Assessment', Report to the Department of Climate Change.

Fawcett, R. and Jones, D. 2008, 'Waiting for Global Warming', National Climate Centre, Australian Bureau of Meteorology, April.

Garnaut, R. 2008, The Garnaut Climate Change Review, Final Report, Cambridge University Press, Cambridge.

Garnaut, R. 2009, 'One Year After the Garnaut Climate Change Review', speech reported at the East Asia Forum blog, 21 September 2009 at: http://www. eastasiaforum.org/2009/09/21/one-year-after-the-garnaut-climate-changereview/

Hansen, J., Sato, M., Kharecha, P., Beerling, D., Berner, R., Masson-Delmotte, V., Pagani, M., Raymo, M., Royer, D. L. and Zachos, J. C. 2008, 'Target Atmospheric $\mathrm{CO}_{2}$ : Where Should Humanity Aim?', Open Atmospheric Science Journal 2: 217-31.

Hoggan, J. 2009, Climate Cover-Up, Greystone Books, Vancouver.

IPPC 2007, Climate Change 2007, Mitigation of Climate Change. Contribution of Working Group III to the Fourth assessment Report of the Intergovernmental Panel on Climate Change, Cambridge University Press, Cambridge, UK and New York, NY, USA.

IPPC 2007b: Climate Change 2007: The Physical Science Basis. Contribution of Working Group 1 to the Fourth Assessment Report of the Intergovernmental Panel on Climate Change, Cambridge University Press, Cambridge, UK and New York, NY, USA.

Kolstad, C. 1994, 'George Bush versus Al Gore: Irreversibilities in Greenhouse Gas Accumulation and emission Control Investment', Energy Policy 22(9): 771-8.

Kolstad, C. 1996, 'Learning and Stock Effects in Environmental Regulation: The Case of Greenhouse Gas Emissions', Journal of Environmental Economics and Management 31(1): 1-18. 
National Academy of Sciences 1979, Carbon Dioxide and Climate: A Scientific Assessment, Washington, DC.

Oreskes, N. 2007, 'The Scientific Consensus on Climate Change: How Do We Know We're Not Wrong?' in DiMento, J. and Doughman, P., Climate Change, MIT Press, Cambridge, MA.

Pindyck, R. 2006, 'Uncertainty in Environmental Economics', National Bureau of Economic Research, Working Paper, 12752, December.

Plimer, I. 2009, Heaven and Earth - Global Warming: The Missing Science, Neilsen Bookscan.

Productivity Commission 2009, 'Government Drought Support, Productivity Commission Inquiry Report', Melbourne.

Stern, N. 2007, The Economics of Climate Change: The Stern Review, Cambridge University Press, Cambridge.

Tamiotti, L., Teh, R., Kulaçoğlu, V., Olhoff, A., Simmons, B. and Abaza, H. 2009, 'Trade and Climate Change WTO-UNEP Report', World Trade Organisation.

The Climate Group 2009, 'Breaking the Climate Deadlock: The Economic Benefits of Collaborative Climate Action', Office of Tony Blair, September.

Nordhaus, W. 2008, A Question of Balance, Yale University Press, New Haven.

Weitzman, M. 2009, 'On Modelling and Interpreting the Economics of Catastrophic Climate Change', Review of Economics and Statistics 91: 1-19.

Woodford, R. T. and Bishop, R. C. 1997, 'How to Decide When Experts Disagree: Uncertainty-Based Choice Rules in Environmental Policy', Land Economics 73(4): 492-507.

Zencey, E. 2009, 'Mr. Soddy's Ecological Economy', The New York Times, 12 April. 


\title{
A New Mind-set for Exchange Rates
}

\author{
STEPHEN GRENVILLE ${ }^{1}$
}

\section{The Old Mind-set}

Following the breakdown of the Bretton-Woods system of fixed exchange rate in the early 1970s, many countries chose to hand over the exchange-rate determination to the financial markets, with a free float. That a free float would deliver the optimal result was presumed by many practitioners and nearly all academics. Harry Johnson (1972) promised that "A freely flexible exchange rate would tend to remain constant so long as underlying economic conditions (including government policies) remain constant; random deviations from the equilibrium level would be limited by the activities of private speculators."

Things turned out very differently, with large fluctuations seemingly unconnected to any change in the 'fundamentals'. The US dollar fluctuated by more than 30 per cent in the mid 1980s. The Japanese yen moved over a range from almost $150 /$ US $\$$ to $80 /$ US $\$$ within a space of three years in the mid 1990s. Smaller currencies such as the Australian dollar fluctuated even more widely. Emerging countries fared worse still, with Latin America in general crisis in the 1980s, Mexico again in 1994, East Asia in 1997 and Russia in 1998. This didn't seem to fit with the idea that 'fundamentals' would change slowly and arbitrageurs would smooth the rate over time. It was not just a matter of short-term volatility (which might not do much harm): as well, there were large and persistent misalignments with sudden readjustments, even for the largest countries with deep and mature financial markets.

Despite this, the faith in the magic of the market - in the free float - remained. Even for emerging countries with immature financial markets, the International Monetary Fund's message was to float and let the market sort it out, with minimal intervention and no capital controls. Fixed rates against the US dollar were seen as the major cause of the Asian crisis of 1997 and the remedy was to float freely.

1 The Lowy Institute, stephengrenville@hotmail.com. 
Two factors have opened up this debate again. First, the Global Financial Crisis has highlighted the imperfections of the market's price-discovery process. ${ }^{2}$ No longer will any debate be stopped in its tracks by making the point: 'You don't think you know better than the market, do you?'

Second, there is now a fair bit of accumulated evidence that what is pejoratively called a 'dirty' float is not only feasible, but can work pretty well. ${ }^{3}$ Few countries have practised the benign neglect implied by a pure free float. A number of countries have run successful exchange-rate regimes which rely on a free market float much of the time, but use market intervention (sometimes quite substantial) when the market doesn't seem to be delivering a sensible answer. Australia provides one of the clearest examples of this. Of course, it is difficult to convince a sceptical audience that the substantial intervention altered the course of the exchange rate: we don't know for sure what would have happened without the intervention. But in the first 20 years of the float, the RBA made a profit of more than $\mathrm{A} \$ 5$ billion through its intervention (Becker and Sinclair 2004). Even Milton Friedman (1953) accepted that if intervention was profitable, there is a powerful presumption that it was stabilizing.

Still the IMF staff remained unconvinced. A working paper detailing the Australian experience concluded: 'The apparent success of intervention in affecting the level of the Australian dollar appears to have come at the expense of increasing volatility of exchange rate movements.' ${ }^{4}$

Australia was not alone in profitable intervention. Japan had similar success (Ito 2002) but, following the adage that 'it is the spouting whale that is harpooned', it has kept a low profile on its intervention.

Still, the received academic wisdom is that sterilised intervention has little or no effect. Simple theoretical models often assume perfect substitutability of assets in different currencies. Empirical work often relied on a heterogeneous mixture of examples. Some intervention episodes, such as the 1992 defence of sterling, reflected politics more than economics and were foredoomed. Certainly, there were enough examples of policy failure where the authorities had attempted

\footnotetext{
2 It is tempting to say that the GFC highlighted serious flaws in the Efficient Markets Hypothesis. The EMH, taken by itself, says no more than that the market price has already taken account of all publicly available information. But its name seemed to promise more than this near-platitude. Combined with the idea that people are rational and that market participants face risk (which can be measured by probabilities) rather than uncertainty, something more loosely styled 'efficient markets' seemed to imply that the price-discovery process would be optimal.

3 See Sarbo and Taylor (2001).

4 Edison, Cashin and Liang (2003). Of course the volatility this paper is testing is daily volatility, irrelevant to the question of stabilization over the course of the cycle. Seeing the profit made by this intervention, some argue that it needs to be discounted for risk. But the usual measures of risk - short-term volatility - are not relevant for long-term position-taking, where the position will not be unwound to meet some short-term liquidity need. The 'risk' for a long-term holder is that the position will be eventually unwound at a loss, and this is fully captured by the profit calculation.
} 
to defend disequilibrium rates. Rather than examine cases where intervention worked well and try to analyse just why it was effective in these cases, these futile interventions were often regressed together with the successes, drawing the general conclusion that intervention was futile at best and harmful at worst.

At the same time that studies were showing intervention to be futile, the best academics also noted something that should have shaken confidence in our understanding of exchange rates. In the early 1980s, Meese and Rogoff (1983) found that no fundamentals-based model of the exchange rate (whether based on purchasing power parity, trade flows, capital flows or interest differentials) could beat the 'random walk' (that today's estimate of the exchange rate is the best estimate of the future rate). In other words, no model could offer any help at all in predicting the path of the exchange rate. Extensive testing in the ensuing quarter-century has left this conclusion unaffected over the short run, although some models fare better at explaining longer-term exchange-rate tendencies (Rogoff 1999).

This amazing result might have taken researchers down either of two paths. It might be that the models were accurately capturing where the equilibrium exchange rate should be and the market was not delivering this answer. Or it could send researchers to develop a theory that could explain the behaviour of the exchange rate. Largely, the latter path was chosen. Researchers worked hard to fit the real world into the EMH, explaining the exchange rate in terms of 'time-varying risk' and other deus ex machina devices.

A more fruitful line of analysis noted that not all market participants based their trading on economic fundamentals. Frankel and Froot (1986) hypothesised that the market comprised both 'fundamentalists' and 'chartists', and sometimes the chartists were dominant. But even those who accepted this hypothesis did not ask whether the policymakers could or should intervene when the chartists were in the ascendancy, taking the rate to non-equilibrium levels. The free market was still sacred, even when it was wrong.

A much smaller group (De Grauwe and Grimaldi 2006) worked on the intuitively plausible idea that while no-one had a precise idea of what the equilibrium exchange rate should be at any moment, it was more useful to think about equilibrium as lying within quite a wide range of 'rational beliefs' (that is, not inconsistent with the evidence). Not only did this explain why the actual market outcome might not correspond to the fundamental equilibrium, but it also explained why the rate could move sharply in response to trivial 'news'. When people are uncertain as to the right rate (and their 'model' of exchangerate formation has a wide margin for error), a random event can cause people to shift their view on what is the equilibrium exchange rate quite substantially and suddenly. 
But this range of rational beliefs is not enough, in itself, to explain the magnitude of the departures from equilibrium. The more extreme movements can only to be explained in terms of market dynamics and endogenous risk. Once the price starts to move, portfolio and accounting constraints force market participants to cut their positions in currencies, even when they believe that the price is already below the equilibrium and will revert in due course.

Why doesn't arbitrage fix the problems? In practice, most arbitrageurs cannot actually take much risk. Very few institutions can hold an open FX position for long. Persistence is a problem for disequilibrium rates: as Keynes is said to have remarked, markets can remain irrational for longer than you can remain solvent.

\section{A New Mind-set}

If we accept that the market price is not always gravitating towards the equilibrium exchange rate, the policy mind-set can and should shift fundamentally, to focus on two questions. What is the equilibrium rate? Can intervention shift the actual rate towards this?

The first question poses a major challenge for policymakers. While a free-float regime does not require the policymakers to have any view at all as to the 'right' exchange rate, the new mind-set requires them to have a view on the equilibrium exchange rate. This is not easy (perhaps impossible) to do with precision, but the answer might well be in the form of a range reflecting the array of 'rational beliefs' (just as inflation targeting sees the acceptable inflation rate as a band rather than a single point).

The second question requires a similar shift in policy mind-set. Instead of assuming that the market has established the equilibrium rate (and therefore any intervention will take the actual rate away from its equilibrium), if the market rate is sub-optimal, this opens the possibility that successful intervention would take the rate towards equilibrium. Then the policy question is an operational one: does the policymaker have the means to shift the rate in the right direction?

This opens up a range of feasible exchange-rate regimes and policies, other than free floating. One approach to the equilibrium issue is the band/basket/crawl (BBC) regime suggested by Williamson (2008). The authorities announce a target band which defines the range in which they believe the equilibrium lies. This allows variation within this band but requires firm intervention at the edges of the band. If the market accepts the band as credible, speculators will not challenge the band (and might even support it: after all, just as the authorities don't know for sure what the 'right' rate is, neither do the speculators). The 
$\mathrm{BBC}$, of course, is in inflation-adjusted real terms and the 'crawl' of the band acknowledges the need for adaptation to the (implicitly slowly changing) fundamentals.

For those who (understandably) worry that countries may be too active in their intervention and will defend a non-equilibrium level for mercantilist reasons, an alternative regime is to establish an internationally endorsed 'reference range' and specifically renounce intervention within this range (a genuflection to the market and acknowledgment that the model is uncertain) but allow intervention once the band is breached.

Others (for example, Australia and Japan) have a more ad hoc approach, intervening when the market seems to be clearly misbehaving, usually only when the market has taken the rate to a clearly incorrect level, where the misalignment is more likely to be harmful.

Policymakers will have to consider that the equilibrium might be changing over time. It will also have a cyclical component. Some temporary departure from the longer-term fundamental equilibrium exchange rate (FEER) over the course of the cycle is desirable (and part of the transmission mechanism of monetary policy) as the exchange rate can usefully 'spill' excess demand into net imports.

The IMF itself has an internal committee which has been wrestling with the notion of the 'right' rate, although its two-fold objectives are carefully defined to avoid endorsing market intervention. The first purpose is to give countries warning if their exchange rate risks causing a crisis (for example, through excessive current-account deficits and too much foreign debt). The second purpose is directed at identifying exchange-rate 'manipulation' (that is, rates which were being held away from their equilibrium by policy, usually for mercantilist reasons) rather than providing a starting point for policy action to shift the actual rate towards its equilibrium. China is a case in point, although it has not been formally declared to be a 'manipulator'.

In the IMF's exchange-rate analysis there are three measures of 'equilibrium' - one akin to Williamson (based on the sustainability of the current account), one based on a macro-model and one depending on the sustainability of foreign debt (closely associated with the Williamson approach). The precise answers are not publicly available, and the routine write-up usually finds that the answers (which often differ significantly between the three methods) are all compatible with the actual rate.

At least at this stage, these attempts lack enough precision and have too many questions about methodology to be the basis of firm policy action, especially of a mechanistic nature. If they are to be the basis of serious discussion, the sensitivities (which at the moment stop the IMF from publishing the exact 
exchange rates which their methodology implies) need to be overcome. But this sort of analysis is the starting point of a new and better policy approach to exchange rates.

The doctrinal fixation with persuading countries to adopt a pure free float has distracted us for three decades from this practical operational task of identifying the equilibrium exchange rate (in terms of a range or central tendency) and devising effective intervention strategies. But the Fund position now seems to have shifted significantly. The Fund has abandoned the 'corner solutions' argument, which said that countries needed to be either rigidly pegged (like Hong Kong) or free floating. The previously infeasible middle ground is now judged to be viable (Gosh and Ostry 2009).

\section{The Challenge}

What is required now is a wider change in the mind-set. We should accept that, while the market is a powerful tool for the discovery of the equilibrium price that may well be right on average and most of the time, at times it goes awry. If this is accepted, then efforts to push the rate towards equilibrium can't be dismissed on the basis of principle or doctrine. It may be difficult to establish the equilibrium with accuracy, and the authorities may have imperfect instruments to influence the exchange rate (so they would not be aiming to achieve the FEER, only to move towards it). But this is a debate which should be joined, and it should be done in the open, without the inhibiting presumption that intervention is a sign of policy inadequacy.

The conceptual mind-set is simple enough: the policymakers should be trying to mimic the equilibrium exchange rate that a well-functioning market would produce. The theoretical attraction of a free-market floating solution was that the financial markets promised to deliver this. This would guard against policymakers attempting to impose their mistaken preconceptions or their mercantilist export-oriented priors on this. It falls down only because the market has shown itself unable to provide this price discovery, at least in a form that is consistent and stable over time. But the key point is that any intervention should be trying to mimic a well-functioning market, not override it to produce a non-equilibrium exchange rate. 'Active' policy must resist the temptation to use the exchange rate for some non-equilibrium purpose - for a mercantilist purpose or to hold the rate at some non-equilibrium level because change is politically unpalatable or harms certain vested interests. 
Will the authorities make mistakes in their interventions? Of course they will, just as they make mistakes with the other policy instruments. But principled inaction is not the answer: to claim innocence on the basis of inaction is no defence if a valid and beneficial policy is available.

There remains a further issue. While we noted that there have been very substantial and sustained shifts in exchange rates, even for countries with deep and mature markets such as Japan and Australia, these shifts seem to have caused few problems, at least as far as can be judged by complaints from those who might have been adversely affected. One curious stylised fact that coincides with the floating-rate period is that the pass-through to domestic inflation seems to have been either small or very slow. Thus the authorities have been prepared to see large downward shifts in the exchange rate without feeling the need to support the currency through higher interest rates. While elements in the tradable-good sector complain from time to time, developed economies seem to have adapted to these large swings in the exchange rate. This can't simply reflect widespread hedging, as the large cumulative external imbalances in both Japan and Australia must have left substantial foreign-exchange exposures. In any case, if exchange-rate changes don't have any effects, we might need to reexamine some core parts of international trade theory.

Thus the policy implications of this paper for the developed countries are small. Japan and Australia will presumably go on intervening, profiting from this intervention but without doing more then 'filling the troughs and lopping the peaks' of the path of the exchange rate over time.

Where this analysis has more practical policy force is with the emerging countries and the advice which the IMF gives to them. Here, the big swings in exchange rates are clearly disruptive. Both Indonesia and South Korea suffered large falls in their exchange rates during the GFC, even though their economies were not directly involved in the crisis. These exchange-rate falls posed a serious threat to financial stability. In both cases, the authorities intervened very substantially, and in both cases the fall was short-lived, justifying the intervention in terms of profitability, at least. Nevertheless, the IMF's reaction, in the case of Korea, was to persuade the authorities that future intervention should be limited to (irrelevant) 'smoothing and testing'. The new doctrine, as espoused by Gosh and Ostry, has not yet filtered down to the Fund's operational staff. It is within that institution that the greatest mind-set change is needed. 


\section{References}

Becker, C. and Sinclair, M. 2004, 'Profitability of Reserve Bank Foreign Exchange Operations: Twenty Years After The Float', Reserve Bank of Australia Research Discussion Paper RDP2004-06.

De Grauwe, P., and Grimaldi, Marianna 2006, The Exchange Rate in a Behavioral Finance Framework, Princeton, NJ: Princeton University Press.

Edison, H., Cashin, P. and Liang, H. 2003, 'Foreign exchange intervention and the Australian dollar: Has it mattered?', IMF Working Paper 03/99.

Frankel, J. A. and Froot, K. A. 1986, 'Understanding the US Dollar in the Eighties: The Expectations of Fundamentalists and Chartists' Economic Record 62: 24-38.

Friedman, M. 1953, 'The Case for Flexible Exchange Rates' in Essays in Positive Economics, Friedman M. (ed.), Chicago: Chicago University Press.

Gosh, A. and Ostry, J. 2009, 'Choosing an exchange rate regime', Finance and Development 46(4).

Ito, T. 2002, 'Is Foreign Exchange Intervention Effective? The Japanese Experiences in the 1990s', NBER Working Paper No. 8914, April.

Johnson, H. 1972, 'The Case for Flexible Exchange Rates' in Further Essays in Monetary Economics, Allen \& Unwin: London.

Meese, R. and Rogoff, K. 1983, 'Empirical Exchange Rate Models of the 1970s: Do They Fit Out of Sample?' Journal of International Economics 14: 3-24.

Rogoff, K. 1999, 'Monetary Models of Dollar/Yen/Euro Nominal Exchange Rates: Dead or Undead?' Economic Journal 109: F655-9.

Sarno, L. and Taylor, M. P. 2001, 'Official Intervention in the Foreign Exchange Market: Is It Effective and, If So, How Does It Work?' Journal of Economic Literature 39(3): 839-68.

Williamson, J. 2008, 'Exchange Rate Economics', Peterson Institute Working Paper 08/03, February. 